\title{
Ekstraksi Judul dan Abstrak Artikel Ilmiah Berbasis Rule
}

\author{
Yosua Setyawan Soekamto, Departemen Sistem Informasi, Universitas Ciputra Surabaya
}

\begin{abstract}
Abstrak-Perkembangan penelitian dan jumlah research paper yang dipublikasikan di berbagai Jurnal, menimbulkan kesulitan pada proses seleksi dan referensi oleh para peneliti dan pengelola jurnal. Dalam research paper bagian judul dan abstrak adalah ide utama dan ringkasan penelitian beserta metode yang digunakan dalam penelitian tersebut. Ekstraksi judul dan ringkasan research paper menjadi topik yang cukup banyak dibahas dengan berbagai metode. Umumnya ekstraksi terbatas dengan penggunaan bahasa dan gaya penulisan tiaptiap jurnal. Dalam penelitian ini, dilakukan ekstraksi judul dan abstrak dengan menggunakan association rule. Penerapannya dilakukan dengan intuisi umum dalam penulisan research paper. Penelitian yang dilakukan menggunakan 2 dataset layout research paper, yaitu bentuk 1 kolom dan 2 kolom. Penelitian ini membantu pengelola jurnal dan peneliti sehingga memudahkan proses referensi secara otomatis dan proses seleksi untuk publikasi jurnal secara online. Rule diterapkan pada gaya penulisan research paper yang umum digunakan, sehingga dapat diterapkan pada berbagai jenis bahasa. Beberapa contoh rule yang digunakan adalah "Judul paper merupakan sebuah kalimat (frase) dengan menggunakan ukuran teks yang paling besar", "Judul paper ditulis pada awal halaman pertama", "Judul paper mayoritas ditulis dengan menggunakan cetak tebal (bold)", "Judul paper diikuti dengan nama penulis", "Judul paper yang muncul di halaman kedua dan selanjutnya sebagai header atau footer memiliki letak yang tidak lazim dibanding isi paper (atau berada di margin halaman)". Hasil penelitian memberikan 98\% kesuksesan memperoleh Judul paper, 76\% memperoleh Abstrak dalam Bahasa Indonesia dan 80\% Abstact dalam Bahasa Inggris.
\end{abstract}

Kata Kunci-Information Extraction, Association Rules, Title Extraction, Abstract Extraction, Text Metadata Extraction.

\section{Pendahuluan}

$\mathrm{D}$ alam meningkatkan kualitas kehidupan, banyak peneliti yang terus mengembangkan ilmu dengan melakukan penelitian di berbagai bidang. Untuk dapat disahkan dan diakui oleh masyarakat, maka peneliti menulis ringkasan hasil penelitiannya ke dalam dokumen yang dikenal sebagai research paper. Research paper ini selanjutnya dipublikasikan ke dalam jurnal, baik dalam skala lokal internal dalam negeri maupun skala internasional. Bagi seorang peneliti, tingkat kualitas research paper dinilai dari

Maret 2020

Yosua Setyawan Soekamto, Departemen Sistem Informasi, Universitas Ciputra Surabaya, Surabaya, Jawa Timur, Indonesia (e-mail: yosua.soekamto@ciputra.ac.id) banyaknya referensi yang merujuk papernya. Sedangkan bagi pengelola jurnal, kualitas jurnal dinilai dari banyaknya research paper yang berkualitas dan juga mempengaruhi tingkat konsistensi publikasi jurnal tersebut.

Sistem ekstraksi umumnya menggunakan proses machine learning dan natural language processing (NLP), sedangkan pada penelitian ini digunakan association rules yang diterapkan pada gaya penulisan (font style) dan struktur penulisan research paper (layout).

\section{TINJAUAN PUSTAKA}

Penelitian tentang ekstraksi pada research paper telah banyak dilakukan tetapi mayoritas menggunakan natural language processing (NLP) sebagai dasarnya [1]. Penggunaan NLP umumnya disertai juga dengan penggabungan machine learning, biasanya bertujuan untuk melatih sistem yang dibangun sehingga dapat beradaptasi dengan research paper yang baru. Sistem seperti ini membutuhkan proses yang relatif cukup lama, karena membutuhkan waktu untuk training dan beradaptasi, selain itu dibutuhkan juga cukup banyak dataset untuk melatihnya.

Penelitian yang lebih lanjut adalah dengan menggunakan metode Neural Network yaitu Back-Propagation [2]. Mulanya dilakukan metode machine learning pada teks di bagian abstrak dan judul dokumen. Dari teks-teks tersebut dilakukan pembobotan unigram, bigram dan trigram (nkata), kemudian dicocokkan dengan keyword yang ditulis oleh penulis dokumen. Proses pencocokan dilakukan dengan dua cara yaitu full-keyword dan partial-keyword. Fullkeyword berarti mencocokkan teks unigram, bigram dan trigram dengan teks keyword utuh dari penulis, termasuk kepanjangan-singkatan yang ditulis penulis, sedangkan partial-keyword adalah mencocokkan dengan n-karakter awal, misalnya cryptogram, cryptography, cryptosystem memiliki kesamana 5-karakter crypt. Selanjutnya dipilih keyword yang memiliki bobot yang tinggi.

Selanjutnya muncul ide baru penelitian yang menggunakan gabungan metode NLP, statistik, rule dan back-propagation [3]. Dalam penelitian tersebut, teks diambil setiap kata dan diberi label jenis kata (kata benda, kata sifat, kata kerja dan seterusnya), lalu dibentuk frase/kalimat kata benda (noun-phrase atau NP). Selanjutnya NP dicari pada judul dan abstrak, jika NP ada di judul maka diberi pembobotan $\mathrm{j}=1$ dan sebaliknya jika ada pada abstrak maka $a=1$. Selanjutnya proses rule-based menyeleksi bobot NP sesuai kemunculan pada judul dan abstrak. Akhirnya hasil dari proses rule-based dimasukkan 
pada proses back-propagation untuk menghitung bobot secara berulang hingga mencapai threshold yang diinginkan.

Fokus penelitian ini adalah merujuk dari karakteristik yang disimpulkan dari penelitian-penelitian rujukan yang disebutkan sebelumnya. Karakteristik pertama yaitu pencarian keyword difokuskan pada bagian judul dan abstrak dokumen. Judul dan abstrak merupakan ide pokok dan rangkuman dari isi dokumen [2],[4],[5]. Penggunaan association rule diharapkan dapat mempercepat proses ekstraksi dan menghemat resource spesifikasi komputer yang dipakai. Rule yang dibuat diadaptasi dengan struktur penulisan research paper seperti urutan-urutan isi research paper, atribut tiap-tiap teks dan bahasa yang digunakan [6],[7],[8].

\section{METODE PENELITIAN}

Metode penelitian menerapkan model rekayasa perangkat lunak (software engineering) secara umum. Awalnya dilakukan analisa pada dokumen-dokumen research paper, mengacu tiga karakteristik yaitu pada bagian judul dan abstrak dokumen, threshold untuk bobot dan pencocokan keyword pada seluruh dokumen; dan mencari karakteristik lain yang menjelaskan struktur penulisan research paper. Dari hasil analisa dibuat desain sistem dengan membentuk rule-rule sederhana dengan threshold-threshold yang bisa dimodifikasi sesuai kebutuhan. Kemudian dilakukan implementasi pembuatan software sesuai dengan rule dan threshold yang sudah didesain, dan melakukan uji coba pada beberapa dokumen research paper. Akhirnya dilakukan pemeliharaan sistem dengan melakukan pembenaran threshold dari hasil uji coba. Proses implementasi, uji coba dan pembenaran threshold ini berlangsung berulang-ulang, sampai ditemukan threshold yang sesuai. Proses ini memang memakan waktu cukup banyak pada saat pembuatan program dibandingkan metode machine learning, tetapi hanya berlaku pada awal pembuatan program ini saja. Jika sudah ditemukan threshold yang memadai, maka dipercaya sistem mampu mengolah dokumen-dokumen lebih cepat dibanding metode machine learning.

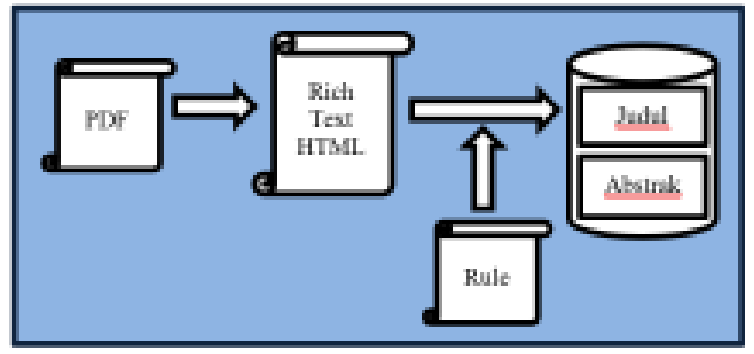

Gambar. 1. Desain Arsitektur Penelitian

Sistem pada mulanya mengubah teks dokumen PDF menjadi rich-text dokumen yang bisa berupa XML atau HTML. Rich-text dokumen yang dimaksud adalah dokumen dengan keterangan-keterangan format penulisan seperti ukuran teks dan hiasan teks (cetak tebal, cetak miring dan sebagainya). Fungsinya adalah mencari teks-teks tertentu yang menjadi judul dan abstrak. Sebagai gambaran umum, teks judul memiliki keunikan penulisan, seperti "ditulis

dengan ukuran paling besar dan dicetak tebal" [8]. Keunikan-keunikan tersebut dituang dalam bentuk association rule yang juga menjadi fokus utama penelitian ini. Proses pengubahan format dari PDF menjadi XML atau HTML menggunakan PDFBox.

Contoh association rules yang digunakan antara lain:

1. "Judul paper ditulis di awal halaman pertama."

2. "Judul paper ditulis dengan ukuran teks paling besar."

3. "Judul paper bisa ditulis dengan menggunakan cetak tebal (bold)."

4. "Abstrak dimulai dengan kata kunci 'abstract' jika menggunakan bahasa Inggris."

5. "Abstrak yang menggunakan bahasa Indonesia dimulai dengan kata kunci 'abstrak' atau 'intisari'."

6. "Paper dapat ditulis dengan 1 kolom atau maksimal 2 kolom."

7. "Jika paper ditulis dengan 1 kolom, maka isi abstrak dipisahkan baris dengan kata kunci-nya."

8. "Jika paper ditulis dengan 2 kolom, maka isi abstrak menjadi satu kesatuan dengan kata kunci-nya."

9. "Jika paper ditulis dengan 2 kolom, maka bagian abstrak ditulis dengan menggunakan cetak tebal (bold)."

10. "Sub-bab dalam paper dipisahkan dengan jeda baris yang cukup jauh (line spacing)"

11. "Jarak line spacing dihitung dengan ukuran teks (font size) yang paling sering muncul, karena font size tersebut menjadi ukuran penulisan paper"

12. "Line spacing yang digunakan dalam paper adalah 1 spasi, kecuali pada judul sub-bab, keterangan gambar, dan keterangan tabel."

Contoh association rules yang ditulis dalam program adalah:

1. IF [node_html] is firstPage THEN add into [candidate_node_html]

2. IF [candidate_node_html].fontSize is maxFontSize THEN add into [candidate_arraylist_title]

3. IF [candidate_arraylist title].fontStyle is boldStyle THEN add into [arraylist_title]

4. IF [candidate_node_html].text in [arraylist_abstracts] THEN add into [candidate_arraylist_abstract]

5. IF [document].layout is havingMoreColumns THEN [document] labeled as twoColumns

6. IF [document].layout isNot havingMoreColumns THEN [document] labeled as oneColumn

7. IF [document] is oneColumn THEN findNextParagraph on [candidate_arraylist_abstract], add into [arraylist abstract]

8. IF [document] is twoColumns THEN add [candidate_arraylist_abstract] into [arraylist_abstract]

9. IF lineDistance([node_html].top, [next_node_html].top) is lowerThan findMostFontSize([node_html]) THEN groupLine([node_html], [next_node_html])

10. IF

[next_node_html].left)

findMostFontSize[node_html])

groupWord([node_html], [next_node_html]) lowerThan THEN 


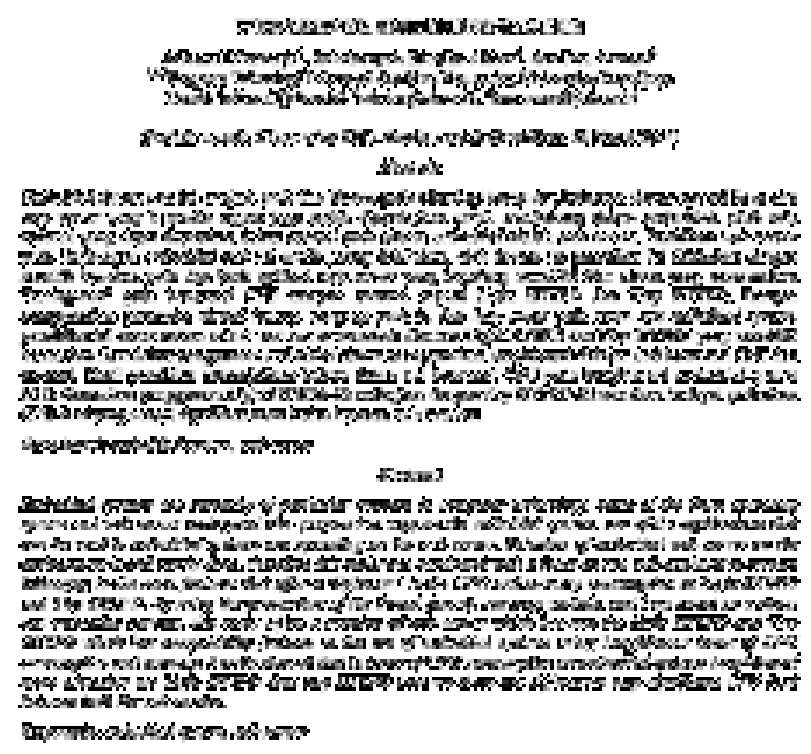

(A)

\section{HASIL PENELITIAN}

Pada penelitian ini digunakan dua jenis dataset yang dibedakan berdasarkan format penulisan research paper (1 kolom atau 2 kolom). Total research paper yang digunakan adalah 50 buah file PDF. PDF diubah menjadi HTML dengan menggunakan open source tool PDFBox yang berbasis bahasa pemrograman Java. Contoh dataset dapat dilihat pada gambar 2, (A) merupakan contoh paper dengan 1 kolom dan (B) merupakan contoh paper dengan 2 kolom.

Untuk menilai kemampuan sistem dari penelitian ini, dilakukan pengecekan secara manual terhadap 50 research paper pada dataset. Pencocokan manual ini bertujuan untuk menghitung nilai accuracy atau error rate dari sistem ekstraksi yang dibuat.

TABEL I

HASIL UJI COBA

\begin{tabular}{|c|c|c|}
\hline Keterangan & Jumlah & Accuracy (\%) \\
\hline \multicolumn{3}{|c|}{ Judul Paper } \\
\hline Benar Ekstrak & 49 & $98 \%$ \\
\hline Salah Ekstrak & 1 & $2 \%$ \\
\hline Total & 50 & $100 \%$ \\
\hline \multicolumn{3}{|c|}{ Abstrak (Bahasa Indonesia) } \\
\hline Benar Ekstrak & 38 & $76 \%$ \\
\hline Salah Ekstrak & 12 & $24 \%$ \\
\hline Total & 50 & $100 \%$ \\
\hline \multicolumn{3}{|c|}{ Abstract (Bahasa Inggris) } \\
\hline Benar Ekstrak & 40 & $80 \%$ \\
\hline Salah Ekstrak & 10 & $20 \%$ \\
\hline Total & 50 & $100 \%$ \\
\hline
\end{tabular}

Dataset yang digunakan adalah research paper yang menggunakan bahasa Indonesia, tetapi memiliki dua bagian abstrak yang ditulis dalam bahasa Indonesia dan bahasa Inggris. Pemilihan dataset berdasarkan tujuan penelitian,
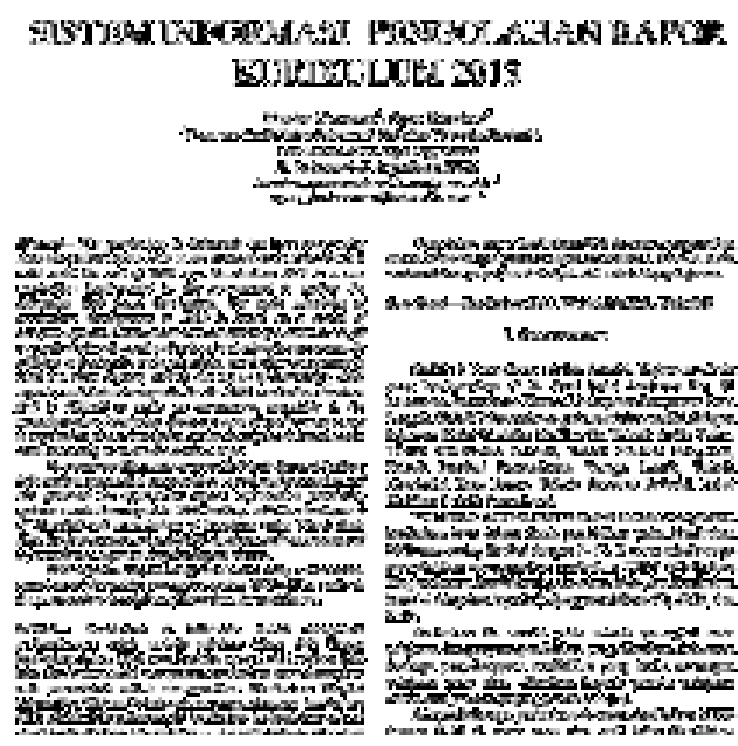

(B)

yaitu membuat sistem ekstraksi yang tidak sepenuhnya bergantung pada ragam bahasa.

Dari hasil uji coba, ditemukan bahwa ekstraksi judul research paper memiliki accuracy rate yang sangat tinggi, yaitu $98 \%$, sedangkan perolehan ekstraksi abstrak berbahasa Indonesia sebesar $76 \%$ dan abstrak berbahasa Inggris sebesar $80 \%$.

Sistem yang dibangun pada penelitian ini tergolong sukses melakukan ekstraksi judul dan abstrak dari research paper. Sistem ini mampu melakukan ekstraksi judul dan abstrak dari dua bentuk paper yang sangat umum digunakan (1 kolom dan 2 kolom). Contoh paper yang digunakan dapat dilihat pada Gambar 2, sedangkan hasil dapat dilihat pada Gambar 3.

Dari hasil pengamatan uji coba bagian abstrak memiliki keterbatasan jika menggunakan bentuk 2 kolom. Penyusunan teks dan pencarian kata kunci lebih sulit jika menggunakan bentuk 2 kolom. Selain itu pada percobaan pada dataset lain, ditemukan abstrak yang terpisah kolom, dan sistem ekstraksi penelitian ini tidak dapat menyatukan isi abstrak tersebut.

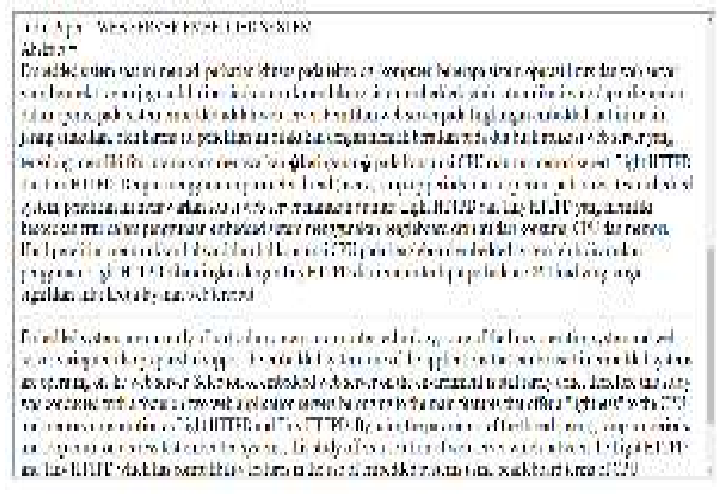

Gambar 3. Output dari gambar 2(A). 
Contoh output yang didapatkan dari sistem ekstraksi penelitian ini terkait dengan contoh pada gambar 2 dapat dilihat pada gambar 3 dan gambar 4. Gambar 3 merupakan output dari research paper pada gambar 2(A). Judul paper yang didapatkan adalah "WEB SERVER EMBEDDED SYSTEM" dan abstrak dalam bahasa Indonesia ditampilkan pada paragraf atas dan abstrak dalam bahasa Inggris ditampilkan pada paragraf bawah. Dalam gambar 3 juga terlihat ada beberapa karakter yang tidak dapat diolah encodingnya.

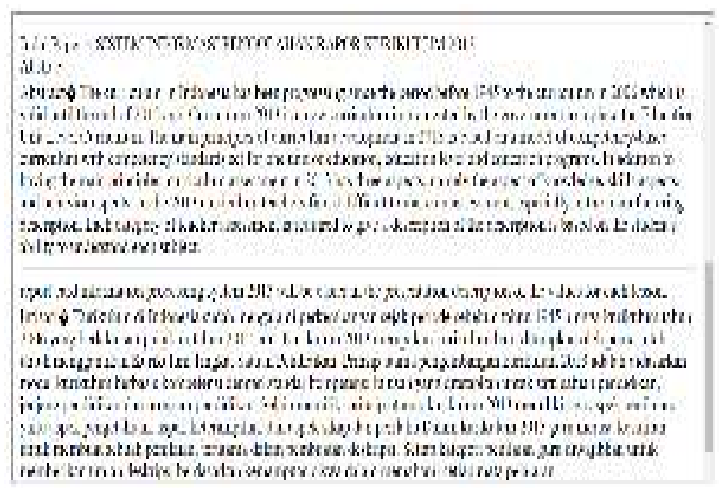

Gambar 4. Output dari gambar 2(B).

Output dari contoh gambar 2(B) ditampilkan pada gambar 4. Hasil judul paper yang diperoleh adalah "SISTEM INFORMASI PENGOLAHAN RAPOR KURIKULUM 2013" dan abstrak yang diperolehpun ditampilkan dalam 2 paragraf. Paragraf yang atas berisi abstrak dalam bahasa Inggris dan paragraf yang bawah berisi abstrak dalam bahasa Indonesia. Pada contoh dataset ini, abstrak bahasa Indonesia diawali dengan kata kunci "Intisari" dan pada ekstraksi ini juga ditemui karakter yang encodingnya tidak dapat diolah. Untuk karakter yang tidak dapat diolah encodingnya tampil sebagai simbol " $?$ ".

Kegagalan ekstraksi pada abstrak disebabkan kesulitan pembatasan paragraf atau segmen bab pada paper. Rule set yang digunakan untuk membatasi antar bab/bagian paper terbukti gagal. Kegagalan ini mengakibatkan sistem tidak dapat menyusun ulang abstrak sehingga dikategorikan sebagai uji coba gagal. Rule set yang digunakan adalah mengukur jarak teks dengan baris atau bagian selanjutnya. Threshold untuk pengukuran jarak ini harus diteliti lebih lanjut sehingga dapat memberikan akurasi yang lebih baik.

\section{KESIMPULAN}

Kesimpulan yang diperoleh dari penelitian ini antara lain:

1. Sistem yang dibangun pada penelitian ini mampu melakukan ekstraksi judul dan abstrak dengan tingkat accuracy yang tinggi, yaitu 98\% untuk memperoleh Judul, $76 \%$ memperoleh abstrak berbahasa Indonesia dan $80 \%$ memperoleh abstrak berbahasa Inggris.

2. Pendekatan menggunakan association rules pada ekstraksi judul dan abstrak terbukti relatif lebih cepat dan memiliki tingkat accuracy yang relatif cukup tinggi.

3. Penggunaan PDFBox harus diikuti dengan pre-proses penyusunan teks kembali, karena cara kerja PDFBox menggunakan segmentasi blok pada teks PDF.
4. Kata kunci untuk mensegmentasi bagian-bagian paper sebaiknya disimpan dalam bentuk text-file sehingga dapat dimodifikasi sesuai dengan penggunaan bahasa pada dataset.

5. Encoding yang digunakan pada PDFBox perlu diperhatikan karena terdapat beberapa karakter khusus yang tidak dapat diolah dengan basis teks.

6. Pada penelitian ini penggunaan association rules tidak menggunakan proses scoring maupun ranking, tetapi hasil bisa saja meningkat jika diberikan scoring pada ekstraksi bagian-bagian isi paper.

7. Threshold jarak antar baris/bagian paper perlu dilakukan perhitungan lebih lanjut, karena akan mempengaruhi akurasi ekstraksi abstrak.

Penelitian ini merupakan bagian awal untuk penelitian keyword extraction dari research paper, sehingga penelitian ini dapat dilanjutkan dengan menggunakan metode NLP dan machine learning untuk mencari kata dasar sebagai bagian keyword extraction. Saran untuk pengembangan selanjutnya adalah meningkatkan accuracy pada bagian abstrak, sehingga dapat mendukung proses keyword extraction.

Keyword extraction yang disinggung pada tinjauan pustaka umumnya melakukan penelusuran pada seluruh teks research paper. Penulis mengusulkan melakukan penelusuran pada bagian judul paper, abstrak dan metode yang digunakan pada research paper. Ketiga bagian tersebut merupakan fokus utama dari research paper, oleh karena itu proses keyword extraction diusulkan dicari pada tiga bagian tersebut, tetapi perlu diwaspadai sistem ekstraksi terjebak pada bagian tinjauan pustaka atau pendahuluan yang umumnya juga memaparkan sebagian metode-metode tetapi bukan metode penelitian utamanya.

\section{ACKNOWLEDGEMENT}

Penulis mengucapkan terima kasih pada Lembaga Penelitian dan Pengabdian Masyarakat Universitas Ciputra Surabaya yang telah membantu mendanai penelitian ini. Penulis juga mengucapkan terima kasih kepada Fakultas Teknologi Informasi yang telah membantu penelitian ini sebagai anggota pakar dalam pengumpulan data.

\section{DAFTAR PUSTAKA}

[1] Frank, Eibe., Witten, Ian H., Paynter, Gordon W., Gutwin, Carl., Nevill-Manning ,Craig G., "Domain Specific Keyphrase Extraction", Proceedings 16th International Joint Conference on Artificial Intelligence. 1999.

[2] Bhowmik, Rekha., "Keyword Extraction from Abstracts and Titles", Proceedings of the IEEE Southeastcon. 2008.

[3] Kavila, Selvani Deepthi, Rajesh, B., Vyshnavi, N., Sushma, K. Moni., "Automatic Key Term Extraction from Research Article using Hybrid Approach", International Journal of Computer Application, Volume 166 No. 6, May. 2017.

[4] Kaur, Jasmeen., Gupta, Vishal., "Effective Approaches for Extraction of Keywords", International Journal of Computer Science, Volume 7, Nov. 2010.

[5] Rose, Stuart., Engel, Dave., Cramer, Nick., Cowley, Wendy., "Automatic Keyword Extraction from Individual Documents", Text Mining: Applications and Theory, 2010.

[6] Guo, Zhixin., Jin, Hai., "A Rule-Based Framework of Metadata Extraction from Scientific Papers", 10th International Symposium on Distributed Computing and Applications to Business, Engineering and Science, 2011. 
[7] Soderland, S., "Learning Information Extraction Rules for SemiStructured and Free Text”, Kluwer Academic Publishers, 1999.

[8] Beel, Joran., Gipp, Bela., Shaker, Ammar., Friedrich, Nick., "SciPlore Xtract: Extracting Titles from Scientific PDF Documents by Analyzing Style Information (Font Size)", Proceedings of the 14th European Conference on Digital Libraries, Volume 6273, Sept. 2010.

[9] Hasan, H. M. Mahedi., Sanyal, Falguni., Chaki, Dipankar., Ali, Md. Haider., "An Empirical Study of Important Keyword Extraction Techniques from Documents", International Conference on Intelligent System and Information Management, Oct. 2017.

[10] Matsuo, Y., Ishizuka, M., "Keyword Extraction from a Single Document using Word Co-Occurrence Statistical Information", International Journal on Artificial Intelligence Tools, Dec. 2003.

[11] Zhang, Chengzhi., Wang, Huilin., Liu Yao., Wu, Dan., Liao, Yi., Wang, Bo., "Automatic Keyword Extraction from Document Using Conditional Random Fields", Journal of Computational Information Systems, 2008.

[12] Witten, Ian H., Paynter, Gordon W., Frank, Eibe., Gutwin, Carl., Nevill-Manning ,Craig G., "KEA: Practical Automatic Keyphrase Extraction", in Proceedings of the 4th ACM Conference on Digital Libraries, 1998.

Yosua Setyawan Soekamto lahir di Surabaya, Jawa Timur, pada tahun 1990. Dia menyelesaikan studi S1 Teknik Informatika Sekolah Tinggi Teknik Surabaya pada tahun 2012 dan studi master Teknologi Informasi Sekolah Tinggi Teknik Surabaya pada tahun 2017. Minat penelitiannya adalah bidang software engineering, software design, web development, information systems dan sedang dalam pembelajaran mobile device programming. 